\title{
Retinal, visual, and refractive development in retinopathy of prematurity
}

This article was published in the following Dove Press journal:

Eye and Brain

20 May 2016

Number of times this article has been viewed

\section{Anne Moskowitz \\ Ronald M Hansen \\ Anne B Fulton}

Department of Ophthalmology, Boston Children's Hospital and Harvard Medical School, Boston, MA, USA
Correspondence: Anne Moskowitz Department of Ophthalmology, Boston Children's Hospital, 300 Longwood Avenue, Boston, MA 02115, USA $\mathrm{Tel}+\mathrm{I} 6173555122$

Fax + I 6175077999

Email anne.moskowitz@childrens. harvard.edu
Abstract: The pivotal role of the neurosensory retina in retinopathy of prematurity (ROP) disease processes has been amply demonstrated in rat models. We have hypothesized that analogous cellular processes are operative in human ROP and have evaluated these presumptions in a series on non-invasive investigations of the photoreceptor and post-receptor peripheral and central retina in infants and children. Key results are slowed kinetics of phototransduction and deficits in photoreceptor sensitivity that persist years after ROP has completely resolved based on clinical criteria. On the other hand, deficits in post-receptor sensitivity are present in infancy regardless of the severity of the ROP but are not present in older children if the ROP was so mild that it never required treatment and resolved without a clinical trace. Accompanying the persistent deficits in photoreceptor sensitivity, there is increased receptive field size and thickening of the post-receptor retinal laminae in the peripheral retina of ROP subjects. In the late maturing central retina, which mediates visual acuity, attenuation of multifocal electroretinogram activity in the post-receptor retina led us to the discovery of a shallow foveal pit and significant thickening of the post-receptor retinal laminae in the macular region; this is most likely due to failure of the normal centrifugal movement of the post-receptor cells during foveal development. As for refractive development, myopia, at times high, is more common in ROP subjects than in control subjects, in accord with refractive findings in other populations of former preterms. This information about the neurosensory retina enhances understanding of vision in patients with a history of ROP, and taken as a whole, raises the possibility that the neurosensory retina is a target for therapeutic intervention.

Keywords: electroretinogram, psychophysics, retinal imaging, photoreceptors, neural retina, refraction

\section{Introduction}

Retinopathy of prematurity (ROP) is among the common retinal neovascular conditions that include diabetic retinopathy, age-related macular degeneration, and central vein occlusion. ${ }^{1}$ ROP is distinguished from these conditions because it occurs in immature retina. Although the disease is mild and resolves spontaneously in the majority of cases, ROP remains a leading cause of avoidable blindness worldwide..$^{2,3}$

ROP has its onset at preterm ages ${ }^{4}$ when the retinal vasculature ${ }^{5-8}$ and the neurosensory retina ${ }^{9}$ are immature (Figure 1). The rod photoreceptors, which are $\sim 20$ times more numerous than the cones, are the last retinal cells to mature, with the exception of the relatively small number of foveal cones. ${ }^{10,11}$ Even the small vessels in the interplexiform layers normally mature earlier than the rods. ${ }^{6}$

As shown in Figure 1, the onset of $\mathrm{ROP}^{4}$ is coincident with the rapid increase in the rhodopsin content of the developing retina. ROP resolves in early post-term 


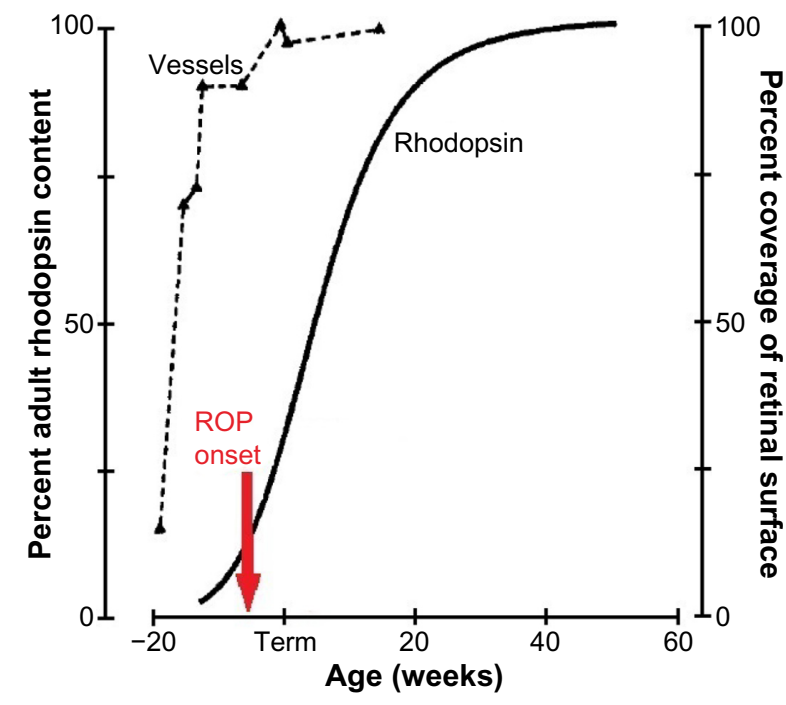

Figure I The developmental increase in rhodopsin content of the retina and temporal retinal coverage by large vessels.

Notes: As rod photoreceptor development proceeds, the rod outer segments elongate and rhodopsin content increases. These measures of rhodopsin extracted from whole retinae are companions for the full-field electroretinography that is used to evaluate rod activity. The red arrow indicates the onset of prethreshold ROP as described by Palmer et al. ${ }^{4}$ Copyright (C) 1999. Association for Research in Vision and Ophthalmology. Adapted from Fulton AB, Dodge J, Hansen RM, Williams TP. The rhodopsin content of human eyes. Invest Ophthalmol Vis Sci. 1999;40(8):I878-I883. ${ }^{74}$ Data for vessel coverage values from Provis JM. Development of the primate retinal vasculature. Prog Retin Eye Res. 2001;20:799-821. ${ }^{6}$

Abbreviation: ROP, retinopathy of prematurity.

weeks ${ }^{12,13}$ when rod outer segment development tails off. Thus, although we are all well aware that the accepted clinical hallmark of ROP is abnormal retinal vasculature, we cannot ignore the involvement of the neural retina in the ROP disease process and the burgeoning metabolic demands of the rapidly developing rods.

We have found evidence that the neurosensory retina is very much involved in the ROP disease process by studying children and rat models of ROP. The escalating metabolic needs of the oxygen-greedy rods are poised to be an instigating factor for ROP. In rat models, rod photoreceptor dysfunction is detectable before retinal vascular abnormalities manifest. ${ }^{14}$ Our longitudinal study of rat models shows that early rod dysfunction predicts the vascular outcome, and not vice versa. ${ }^{15-18}$ We have shown that 1 ) recovery of the ROP rat's post-receptor retinal sensitivity and retinal vasculature is under the cooperative control of growth factors, which in other neural tissues mediate neural-vascular crosstalk ${ }^{19}$ and 2) pharmacological lessening of the developing rod's metabolic needs improves the vascular outcome. ${ }^{20}$ In children, there are significant effects on retinal and visual function and eye growth long after the clinical resolution of ROP; key results are presented below. In short, rods are involved before, during, and after active ROP.
The subjects in our studies met the criteria for ROP screening ${ }^{21}$ and underwent serial examinations in the neonatal intensive care unit, the frequency of which was based on the program of examinations in the multicenter ROP trials (CRYO-ROP and ETROP). ${ }^{22,23}$ We categorized the subjects as having had severe ROP, mild ROP, or no ROP, as shown in Table 1. This categorization was based on the International Committee for the Classification of Retinopathy of Prematurity (ICROP) system ${ }^{24}$ whereby the site of the disease is specified by zone (I-III from central to peripheral), the extent within the zone by number of affected clock hours (1-12), and disease severity by stage ( $1-5$ from mild to complete retinal detachment).

Through a series of non-invasive studies of the neurosensory retina in human ROP subjects, we have found persistent effects on rod photoreceptor function and evidence of intralaminar re-organization of post-receptor retina. These studies have employed electroretinogram (ERG), ${ }^{25}$ psychophysical, ${ }^{26,27}$ and retinal imaging procedures. ${ }^{28,29} \mathrm{We}$ have also found significant departures from normal in eye growth $^{30}$ and refractive development. ${ }^{31,32}$

\section{Peripheral retina in ROP}

In our ERG studies, we recorded and analyzed rod photoreceptor activity represented in the a-wave and the rod-driven post-receptor activity represented in the b-wave (Figure 2) using procedures described previously. ${ }^{33-36}$ In infants with a history of ROP (median age 10 weeks post-term), both rod and rod-driven post-receptor sensitivity were low. ${ }^{25} \mathrm{In}$ children (median age 10 years), post-receptor sensitivity normalizes but the deficits in rod photoreceptor sensitivity persist even if the ROP had been mild. ${ }^{25}$ These ERG data are evidence that after clinical healing (judged by inspection of the retinal vasculature), the post-receptor neural circuitry undergoes intralaminar reorganization. ${ }^{37-42}$ This is accompanied by effects on rod-mediated visual sensitivity that are demonstrated by our psychophysical studies. ${ }^{26,27}$

We tested rod-mediated vision to evaluate spatial and temporal summation in older children with a history of ROP and in control subjects. ${ }^{26,27}$ The underlying concept of spatial

Table I Classification of subjects in our ROP studies

\begin{tabular}{ll}
\hline Category & Clinical features \\
\hline Severe ROP & Zone III, stage 3; treated by laser \\
Mild ROP & Zone II or III, stage I or 2; resolved \\
& spontaneously without requiring treatment \\
No ROP & ROP never detected \\
\hline
\end{tabular}

Abbreviation: ROP, retinopathy of prematurity. 
A

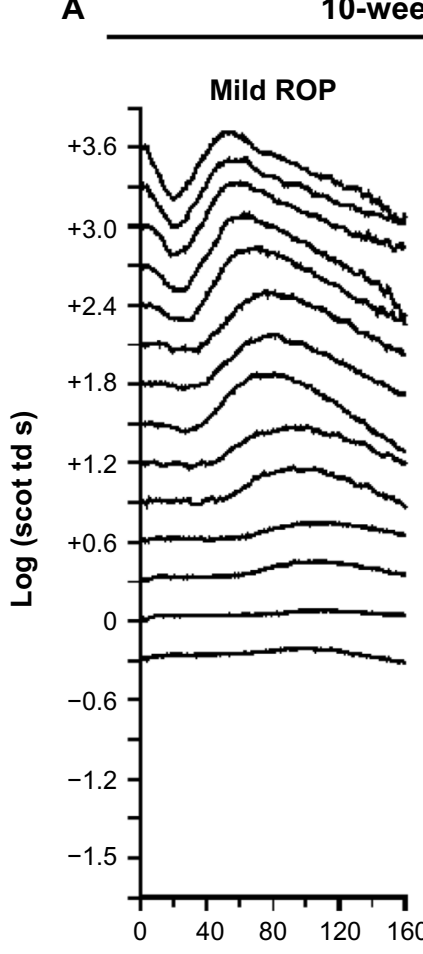

Adult

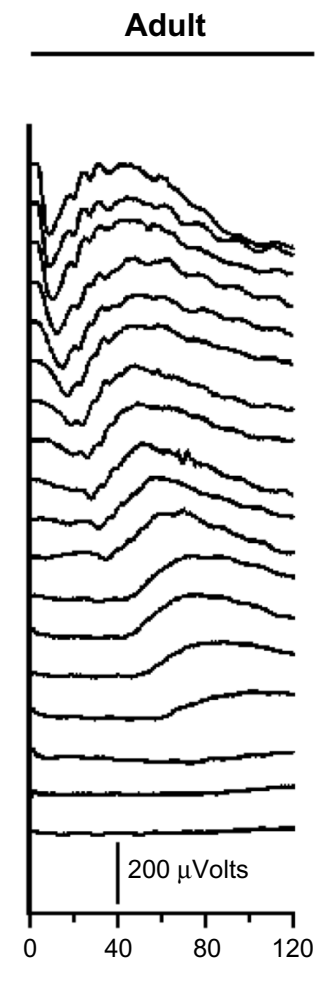

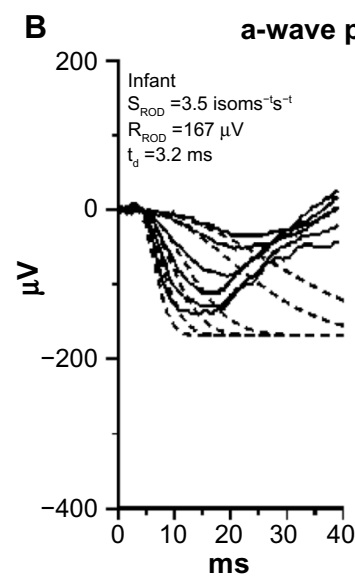

-wave parameters
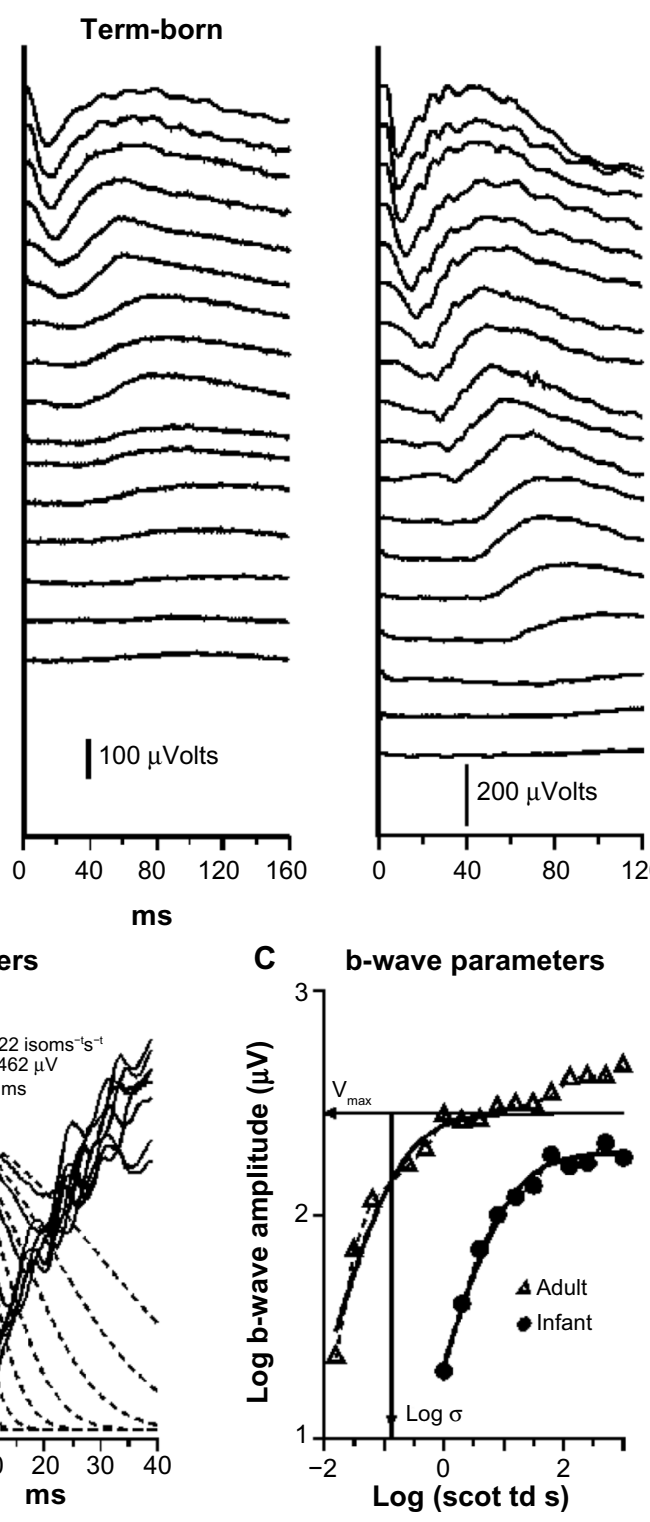

Figure 2 Sample rod-mediated ERG responses to full-field stimuli.

Notes: (A) Responses from an infant with a history of mild ROP and a healthy term-born 10-week-old infant, both tested at 10 weeks post-term, and from an adult. For all three sets of records, the vertical axis indicates the strength of the stimulus flash in log scotopic trolands and the horizontal axis indicates time in milliseconds. For both infant and adult, the amplitude of the response increases with increasing stimulus strength. At lower intensities, b-waves, but no a-waves, are seen. At higher strengths, the downward going a-wave appears. In these test conditions, the a-wave represents the molecular events involved in the activation of phototransduction in the rod outer segments. The b-wave represents post-receptor activity, including that in the rod-driven bipolar cells. (B) A-wave model fits. An expanded view of the a-waves of term-born infant and adult subject is shown. The solid lines are the ERG traces. The dashed lines show the fit of the mathematical Lamb and Pugh model of rod phototransduction, as modified by Hood and Birch, to the a-waves. ${ }^{75-77}$ The model parameters obtained by this calculation are shown on each panel. Rod sensitivity, $\mathrm{S}_{\text {ROD }}$, is lower in the infant than in the adult. In the normally developing eye, $\mathrm{S}_{\mathrm{ROD}}$ is scaled by the rhodopsin content of the retina. (C) Log-log plot of b-wave stimulus/response functions of term-born infant (circles) and adult (triangles). The b-wave amplitude is shown as a function of stimulus strength. The smooth curve fit to the data of each subject represents the function $\mathrm{V} / \mathrm{V}_{\text {MAX }}=\mathrm{I} /(\mathrm{l}+\sigma)$. $^{78} \mathrm{The}$ saturated amplitude, $\mathrm{V}_{\mathrm{MAX}}$, and the stimulus (I) that produces a half maximum amplitude response, log $\sigma$, are indicated for the adult subject. Log $\sigma$ is an index of rod-mediated post-receptor retinal sensitivity.

Abbreviations: ERG, electroretinogram; ROP, retinopathy of prematurity.

summation is that a large number of rods in a given retinal region connect to a neuron; the receptive field is the restricted post-receptor region onto which this group of photoreceptors converge. In our spatial summation test, ${ }^{27}$ the diameter of a test spot was varied; the dark adapted threshold for the detection of the test spot was measured for eight different spot diameters, ranging from $0.4^{\circ}$ (tiny) to $10^{\circ}$ (big - about the diameter of a soft ball at arm's length). The results (Figure 3) show that the critical diameter is larger in subjects with a history of ROP than in preterm subjects who never had 

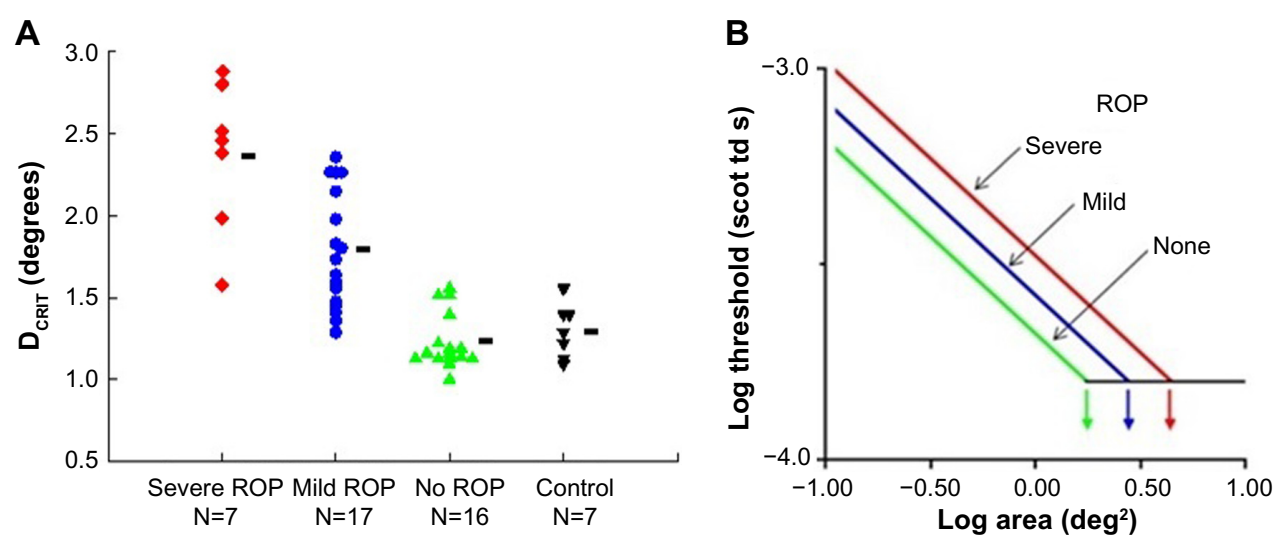

Figure 3 Rod-mediated spatial summation.

Notes: $(A) D_{C R I T}$ values in severe ROP, mild ROP, no ROP, and term-born control groups are plotted. Each point represents an individual subject; the number of subjects in each group is indicated. The horizontal bars indicate the mean $D_{\text {CRIT }}$ value for each group. (B) The log-log plot demonstrates that reciprocity held. In every subject group, for the smaller spots, threshold became lower (more sensitive) with increasing stimulus area. For larger diameter spots, the threshold did not change; summation was complete. (A) Copyright (C) 2014. Association for Research in Vision and Ophthalmology. Adapted from Hansen RM, Tavormina JL, Moskowitz A, Fulton AB. Effect of retinopathy of prematurity on scotopic spatial summation. Invest Ophthalmol Vis Sci. 2014;55(5):331 I-33।3. ${ }^{27}$

Abbreviations: $\mathrm{D}_{\mathrm{CRIT}}$, critical diameter; ROP, retinopathy of prematurity.

ROP and term-born controls. In other words, visual signals are integrated over a larger area (larger receptive field) in ROP subjects; the larger receptive field benefits visual sensitivity. This is further evidence of intralaminar re-organization of the post-receptor ROP retina.

Temporal summation is an indicator of the kinetics of phototransduction in the photoreceptors. In our rod-mediated temporal summation test ${ }^{26}$ the duration of a constant diameter test spot $\left(10^{\circ}\right)$ was varied and the dark adapted threshold for the detection of the test spot was measured for eight different durations, ranging from brief $(10 \mathrm{~ms})$ to long $(640 \mathrm{~ms})$. The results (Figure 4) show that the critical duration is longer in subjects with a history of ROP than in preterm subjects who never had ROP and term-born controls. This is a consequence of the slow kinetics of activation of rod phototransduction in ROP, in accord with the ERG a-wave results. ${ }^{5}$

For both spatial and temporal summation, reciprocity prevailed. ${ }^{26,27}$ That is, as indicated by the diagonal lines with slope -1 on the $\log -\log$ plots shown in the right panels in Figures 3 and 4, the subjects could detect a light ten times dimmer if the stimulus was ten times bigger or ten times longer. Once a critical large size or long duration was reached, the threshold remained about the same as the stimulus size or duration increased.

In an adaptive optical coherence tomography (OCT) study of the retinal laminae at 18 degrees temporal eccentricity, we found a higher ratio of post-receptor to photoreceptor thickness in ROP subjects than in term-born control subjects. ${ }^{43}$ In
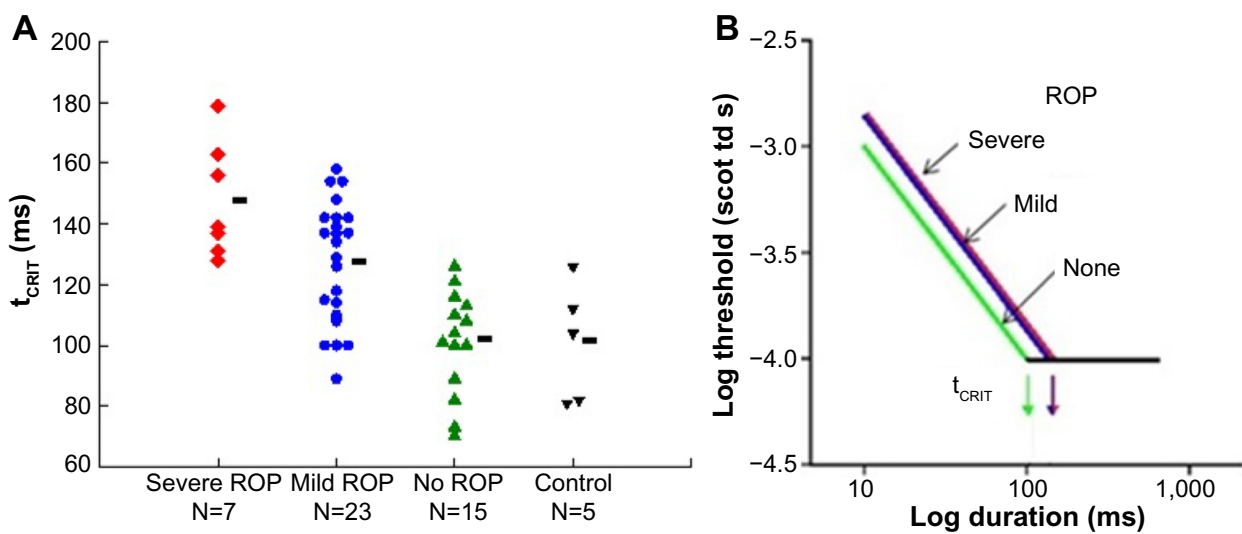

Figure 4 Rod-mediated temporal summation.

Notes: $(\mathbf{A}) \mathrm{t}_{\mathrm{CRIT}}$ values in former preterm subjects with a history of severe ROP, mild ROP, and no ROP and in term-born controls are plotted. Each point represents individual subjects; the number of subjects in each group is indicated. The horizontal bars indicate the mean $t_{\text {CRIT }}$ value for each group. (B) As shown in the log-log plot, reciprocity held. In every subject group, for the brief duration stimuli, threshold became lower (more sensitive) with increasing stimulus duration. For longer duration stimuli, the threshold did not change; summation was complete. (A) Copyright (c) 2015. Association for Research in Vision and Ophthalmology. Adapted from Hansen RM, Moskowitz A, Tavormina JL, Bush JN, Soni G, Fulton AB. Temporal summation in children with a history of retinopathy of prematurity. Invest Ophthalmol Vis Sci. 20I5;56(2):9I4-9I7.26

Abbreviations: $\mathrm{t}_{\mathrm{CRIT}}$, critical duration; ROP, retinopathy of prematurity. 


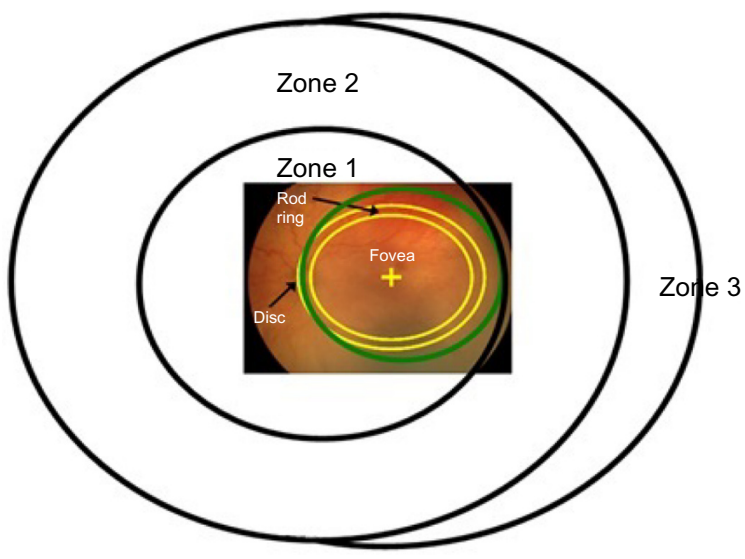

Figure 5 Diagram of the International Classification of Retinopathy of Prematurity zones $^{24}$ with a superimposed fundus photograph on which the optic disc and fovea are indicated.

Notes: The green circle indicates the region of retina viewed through a 28 diopter lens used with the indirect ophthalmoscope. The band delineated by the yellow lines represents the location of the anatomical "rod ring", ' which is an annular region in which there is a high density of rods. The ring is concentric with the fovea and passes just nasal to the optic disc and approximately $18^{\circ}$ temporal to the fovea.

retinal degenerative disorders, thickened inner retinal laminae are reported in those retinal regions where the photoreceptors are disturbed or lost ${ }^{44}$ and are postulated to be the retina's compensation for altered photoreceptor inputs to the postreceptor retina.

\section{Central retina in ROP}

This region includes the fovea and the macula. Both cones and rods are found in ROP zone 1 (Figure 5). ${ }^{24}$ The most commonly measured visual function, visual acuity, is mediated by the foveal cones. Acuity deficits in ROP patients are common, even if the ROP had been successfully treated or was mild and, by clinical criteria, resolved completely. Most of the 15-year alumni of the CRYO-ROP study ${ }^{45}$ and two-thirds of the 6 -year alumni of the ETROP study ${ }^{46}$ had acuity poorer than 20/40.

The central retina matures relatively late. For instance, the outer segments of the rods central to the ring undergo later developmental elongation than those peripheral to the ring. There is a functional parallel. In healthy infants, dark adapted visual thresholds central to the ring mature more slowly than those peripheral to the ring. ${ }^{47,48}$

We hypothesized that this late maturing central region is particularly vulnerable to ROP. Through a series of non-invasive studies of the central retina in subjects with a history of mild ROP, we found 1) delayed maturation of rod-mediated retinal sensitivity using psychophysical procedures, ${ }^{49}$ 2) deficits in cone-driven post-receptor activity using the multifocal ERG (mfERG), ${ }^{50}$ and 3 ) persistent abnormalities of the intraretinal vasculature using adaptive optics retinal imaging. ${ }^{28}$
In our longitudinal psychophysical study of infants with a history of mild ROP, ${ }^{49}$ we found that, even though the clinical disease had resolved spontaneously and completely by term, dark adapted visual thresholds showed a protracted course of development that continued until 18 months post-term, whereas in term-born controls, the thresholds were mature by age 6 months.

The mfERG provides topographical information about the central retina. ${ }^{51}$ Cone-driven bipolar cells (post-receptor retina) are the main contributors to $\mathrm{mfERG}$ responses. ${ }^{52}$ We found that mfERG responses were significantly smaller in subjects with a history of mild ROP than in control subjects (Figure 6, color 3-D plots). ${ }^{50}$ This result led us to hypothesize that bipolar cell density differs between ROP and control subjects. Using adaptive optics retinal imaging (Figure 6), ${ }^{28}$ we found that the foveal pit in mild ROP eyes was significantly shallower than in control eyes and that the inner retinal laminae of foveal and extrafoveal regions were significantly thicker in ROP eyes than in control eyes. This is evidence of failure of centrifugal movement of the bipolar cells during foveal development in ROP, as others have also concluded. ${ }^{53}$

What leads to abnormal foveal structure ${ }^{28}$ and function ${ }^{50}$ in ROP? What goes wrong in the neurovascular development of the central retina in prematurely born subjects? These important issues remain under investigation. The absence of foveal avascular zone and hypoperfusion of this important retinal region during development have been discussed as contributing factors $^{54}$ There is also OCT evidence of cystoid macular edema in ROP infants. ${ }^{55}$

\section{Refractive development}

Numerous studies have shown a high incidence of refractive errors, particularly myopia, in infants born prematurely. ${ }^{31,56-62}$ Although these findings suggest a disturbance in the normal regulation of ocular growth, the mechanisms have yet to be specified. It seems unlikely that the mechanisms that are operational in experimental myopia ${ }^{63-65}$ are applicable to ROP. Interestingly, we have noted that in ROP infants, low rod photoreceptor sensitivity, as determined by analysis of the scotopic ERG a-wave, predicted later myopia. ${ }^{32}$ Deficits in cone ERG responses have been reported in chicks with form deprivation myopia. ${ }^{66}$

We have developed a model of normal eye growth and applied it to the growth of ROP eyes. ${ }^{30}$ Through analysis of extant magnetic resonance images (MRI), we found that the growth of the ROP eye is slow and results in eyes that are shorter and have steeper corneas and thicker lenses compared 


\section{Control}

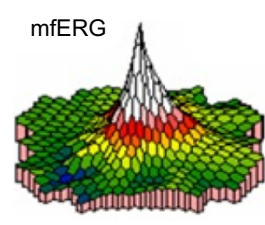

En face OCT

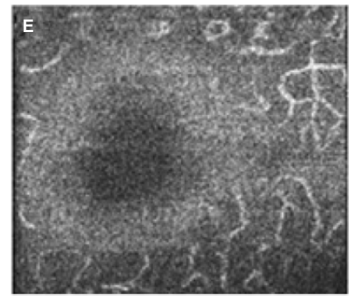

OCT
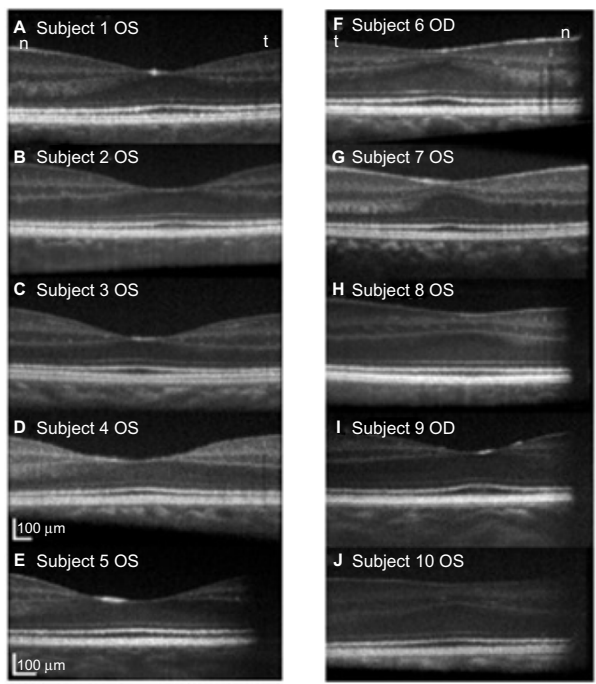

Mild ROP
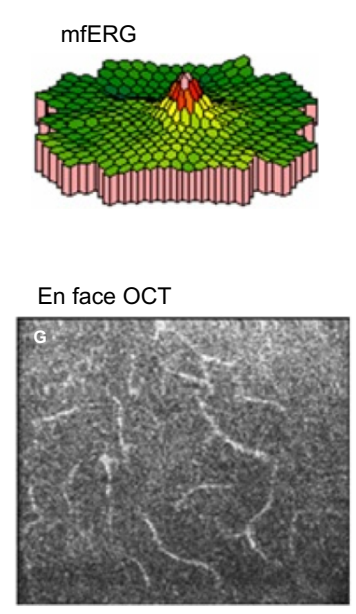

Figure 6 Adaptive optics OCT images of ROP and control subjects.

Notes: A subset of the ROP subjects $(n=5)$ who had participated in our mfERG study ${ }^{50}$ also participated in the imaging study. ${ }^{28}$ In the center panels, OCT images of controls (left) and ROP subjects (right) are shown. The slices were taken through the fovea. On each image, the subject number and eye are indicated. The main findings were significantly shallower pits and significantly thicker post-receptor laminae in the ROP subjects than in the control subjects. En face images of the outer plexiform layer show a clear foveal avascular zone in the controls, but the ROP subjects had abnormal vessels that traversed the foveal region. OCT images Copyright (C) 2008. Association for Research in Vision and Ophthalmology. Reproduced from Hammer DX, Iftimia NV, Ferguson RD, et al. Foveal fine structure in retinopathy of prematurity: an adaptive optics Fourier domain optical coherence tomography study. Invest Ophthalmol Vis Sci. 2008;49(5):206I-2070. ${ }^{28}$ Color-coded 3-D topographical mfERG response density maps are shown for a control subject (upper left) and for a subject with a history of mild ROP (upper right).

Abbreviations: mfERG, multifocal ERG; OCT, optical coherence tomography; OD, right; OS, left; ROP, retinopathy of prematurity; ILM, inner limiting membrane; NFL, nerve fiber layer; GCL, ganglion cell layer; IPL, inner plexiform layer; INL, inner nuclear layer; OPL, outer plexiform layer; ONL, outer nuclear layer; ELM, external limiting membrane; CC, connecting cilium; RPE, retinal pigment epithelium; C, choroid.

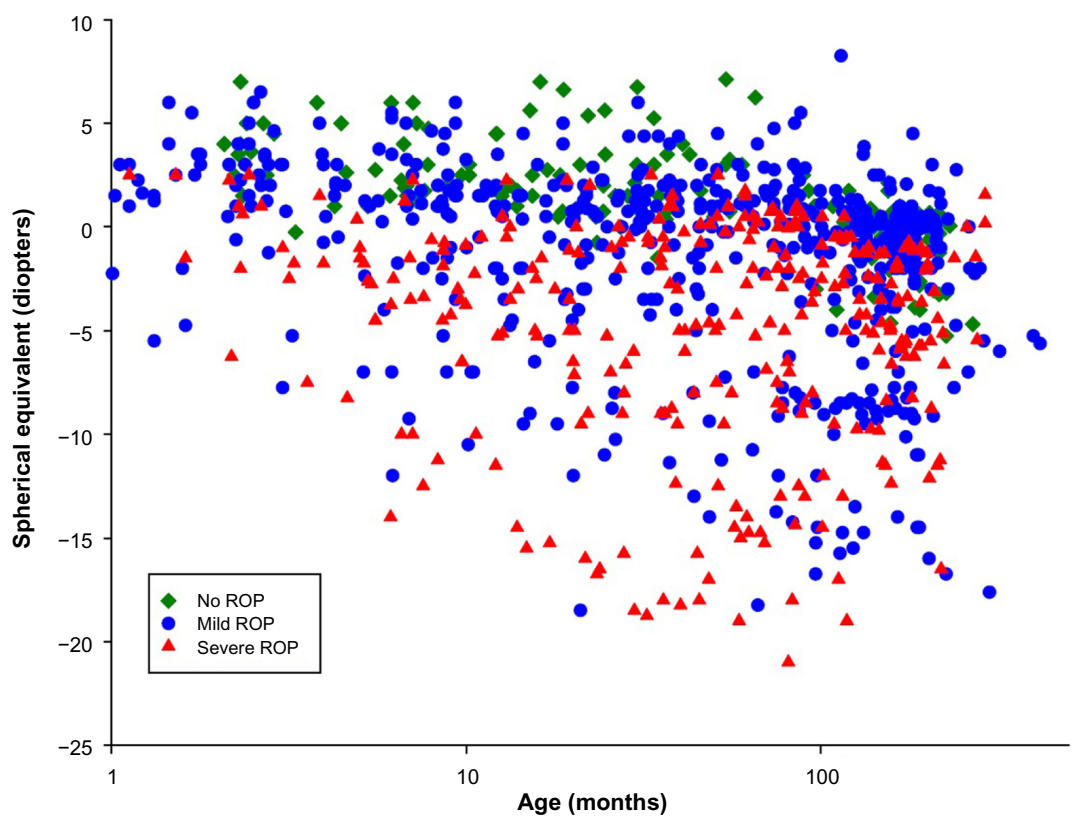

Figure 7 Spherical equivalent refraction (diopters) as a function of age (months).

Notes: Data are shown for 1,027 refractions of the right eye in 279 prematurely born subjects. One to 19 (median =2) refractions were performed on an individual; all refractions are shown. Green diamonds: 158 refractions from 78 subjects who never developed ROP; blue circles: 568 refractions from I54 subjects who had mild ROP; red triangles: 301 refractions from 47 subjects who had severe ROP.

Abbreviations: ROP, retinopathy of prematurity; PL, prediction limit. 
with those in preterm eyes without a history of ROP and in term-born eyes. Refractive development has also been studied in a rat model of ROP ${ }^{67,68}$ more work is needed to translate these findings to the human ROP eye.

Figure 7 shows the results of refractions performed on 279 of our ROP subjects. These data are in reasonable accord with refractions in other populations of former preterms. Compared with the prediction limits for normal refractive development, ${ }^{69,70}$ myopia was more frequent in subjects with ROP than in preterm born subjects who never developed ROP and term-born control subjects. In the preterm subjects who never had ROP, myopia seldom occurred, whereas hyperopia was quite common. Previously reported data showed that, in ROP subjects with myopia, the magnitude of myopia typically increased with age. ${ }^{31}$ We are attempting to unravel the mechanisms that underlie refractive development in ROP by analyzing animal models of ROP, ${ }^{67,68}$ and have developed a human model eye to facilitate studies in infants and children. ${ }^{30}$

\section{Conclusion}

Non-invasive investigation of former preterms, conceived within a framework of molecular and cellular processes known to occur in normal developing human retina and rat models of $\mathrm{ROP},{ }^{6,19,71-73}$ yields a numeric description of retinal, visual and refractive development in these infants and children. Taken as a whole, these data derived from electroretinographic, psychophysical and retinal imaging studies link the children's results to the molecular and cellular processes. From a practical perspective, this body of information contributes to the understanding of vision in children with a history of ROP. Recognition that the neurosensory retina has a role in ROP opens the possibility of future novel therapeutic approaches to ROP.

\section{Acknowledgment}

Supported by National Eye Institute Grant R01 EY-010597.

\section{Disclosure}

The authors report no conflicts of interest in this work.

\section{References}

1. Al-Shabrawey M, Elsherbiny M, Nussbaum J, Othman A, Megyerdi S, Tawfik A. Targeting neovascularization in ischemic retinopathy: recent advances. Expert Rev Ophthalmol. 2013;8(3):267-286.

2. World Health Organization. Vision2020 Report: Global Initiative for the Elimination of Avoidable Blindness, Action Plan 2006-2011. Geneva: World Health Organization; 2007.

3. Steinkuller PG, Du L, Gilbert C, Foster A, Collins ML, Coats DK. Childhood blindness. J Aapos. 1999;3(1):26-32.
4. Palmer EA, Flynn JT, Hardy RJ, et al. Incidence and early course of retinopathy of prematurity. The Cryotherapy for Retinopathy of Prematurity Cooperative Group. Ophthalmology. 1991;98(11): 1628-1640.

5. Fulton AB, Hansen RM, Moskowitz A, Akula JD. The neurovascular retina in retinopathy of prematurity. Prog Retin Eye Res. 2009;28(6): $452-482$.

6. Provis JM. Development of the primate retinal vasculature. Prog Retin Eye Res. 2001;20(6):799-821.

7. Provis JM, Hendrickson AE. The foveal avascular region of developing human retina. Arch Ophthalmol. 2008;126(4):507-511.

8. Provis JM, Leech J, Diaz CM, Penfold PL, Stone J, Keshet E. Development of the human retinal vasculature: cellular relations and VEGF expression. Exp Eye Res. 1997;65(4):555-568.

9. Hendrickson AE. The morphologic development of human and monkey retina. In: Albert DM, Jakobiec FA, eds. Principles and Practice of Ophthalmology: Basic Sciences. Philadelphia: WB Saunders; 1994: 561-577.

10. Curcio CA, Sloan KR, Kalina RE, Hendrickson AE. Human photoreceptor topography. J Comp Neurol. 1990;292(4):497-523.

11. Osterberg G. Topography of the layer of rods and cones in the human retina. Acta Ophthal Suppl. 1935;6:1-103.

12. Ni YQ, Huang X, Xue K, et al. Natural involution of acute retinopathy of prematurity not requiring treatment: factors associated with the time course of involution. Invest Ophthalmol Vis Sci. 2014;55(5): 3165-3170.

13. Repka MX, Palmer EA, Tung B. Involution of retinopathy of prematurity. Cryotherapy for Retinopathy of Prematurity Cooperative Group. Arch Ophthalmol. 2000;118(5):645-649.

14. Reynaud X, Hansen RM, Fulton AB. Effect of prior oxygen exposure on the electroretinographic responses of infant rats. Invest Ophthalmol Vis Sci. 1995;36(10):2071-2079.

15. Akula JD, Hansen RM, Martinez-Perez ME, Fulton AB. Rod photoreceptor function predicts blood vessel abnormality in retinopathy of prematurity. Invest Ophthalmol Vis Sci. 2007;48(9):4351-4359.

16. Akula JD, Mocko JA, Moskowitz A, Hansen RM, Fulton AB. The oscillatory potentials of the dark-adapted electroretinogram in retinopathy of prematurity. Invest Ophthalmol Vis Sci. 2007;48(12): 5788-5797.

17. Liu K, Akula JD, Falk C, Hansen RM, Fulton AB. The retinal vasculature and function of the neural retina in a rat model of retinopathy of prematurity. Invest Ophthalmol Vis Sci. 2006;47(6):2639-2647.

18. Liu K, Akula JD, Hansen RM, Moskowitz A, Kleinman MS, Fulton AB. Development of the electroretinographic oscillatory potentials in normal and ROP rats. Invest Ophthalmol Vis Sci. 2006;47(12): 5447-5452.

19. Akula JD, Mocko JA, Benador IY, et al. The neurovascular relation in oxygen-induced retinopathy. Mol Vis. 2008;14:2499-2508.

20. Akula JD, Hansen RM, Tzekov R, et al. Visual cycle modulation in neurovascular retinopathy. Exp Eye Res. 2010;91(2):153-161.

21. Fierson WM. American Academy of Pediatrics Section on Ophthalmology, American Academy of Ophthalmology, American Association for Pediatric Ophthalmology and Strabismus, American Association of Certified Orthoptists. Screening examination of premature infants for retinopathy of prematurity. Pediatrics. 2013;131(1): 189-195.

22. Cryotherapy for Retinopathy of Prematurity Cooperative Group. Multicenter trial of cryotherapy for retinopathy of prematurity cooperative group. Arch Ophthalmol. 1988;106(4):471-479.

23. Early Treatment for Retinopathy of Prematurity Cooperative Group. Revised indications for the treatment of retinopathy of prematurity: results of the early treatment for retinopathy of prematurity randomized trial. Arch Ophthalmol. 2003;121(12):1684-1694.

24. International Committee for the Classification of Retinopathy of Prematurity. The international classification of retinopathy of prematurity revisited. Arch Ophthalmol. 2005;123(7):991-999.

25. Harris ME, Moskowitz A, Fulton AB, Hansen RM. Long-term effects of retinopathy of prematurity (ROP) on rod and rod-driven function. Doc Ophthalmol. 2011;122(1):19-27. 
26. Hansen RM, Moskowitz A, Tavormina JL, Bush JN, Soni G, Fulton AB. Temporal summation in children with a history of retinopathy of prematurity. Invest Ophthalmol Vis Sci. 2015;56(2):914-917.

27. Hansen RM, Tavormina JL, Moskowitz A, Fulton AB. Effect of retinopathy of prematurity on scotopic spatial summation. Invest Ophthalmol Vis Sci. 2014;55(5):3311-3313.

28. Hammer DX, Iftimia NV, Ferguson RD, et al. Foveal fine structure in retinopathy of prematurity: an adaptive optics Fourier domain optical coherence tomography study. Invest Ophthalmol Vis Sci. 2008;49(5): 2061-2070.

29. Ramamirtham R, Garima S, Akula JD, et al. Extrafoveal cone packing density and geometry in retinopathy of prematurity (ROP). Invest Ophthalmol Vis Sci. 2015;56:ARVO E-Abstract 4933.

30. Munro RJ, Fulton AB, Chui TY, et al. Eye growth in term- and pretermborn eyes modeled from magnetic resonance images. Invest Ophthalmol Vis Sci. 2015;56(5):3121-3131.

31. Lue CL, Hansen RM, Reisner DS, Findl O, Petersen RA, Fulton AB. The course of myopia in children with mild retinopathy of prematurity. Vision Res. 1995;35(9):1329-1335.

32. Moskowitz A, Hansen RM, Fulton AB. Early ametropia and rod photoreceptor function in retinopathy of prematurity. Optom Vis Sci. 2005;82(4):307-317.

33. Fulton $A B$, Hansen RM. Electroretinogram responses and refractive errors in patients with a history of retinopathy prematurity. Doc Ophthalmol. 1995;91(2):87-100.

34. Fulton AB, Hansen RM. The development of scotopic sensitivity. Invest Ophthalmol Vis Sci. 2000;41(6):1588-1596.

35. Fulton AB, Hansen RM, Petersen RA, Vanderveen DK. The rod photoreceptors in retinopathy of prematurity: an electroretinographic study. Arch Ophthalmol. 2001;119(4):499-505.

36. Fulton AB, Hansen RM, MoskowitzA. The cone electroretinogram in retinopathy of prematurity. Invest Ophthalmol Vis Sci. 2008;49(2): 814-819.

37. Jones BW, Kondo M, Terasaki H, Lin Y, McCall M, Marc RE. Retinal remodeling. Jpn J Ophthalmol. 2012;56(4):289-306.

38. Marc RE, Jones BW, Anderson JR, et al. Neural reprogramming in retinal degeneration. Invest Ophthalmol Vis Sci. 2007;48(7):3364-3371.

39. Marc RE, Jones BW, Watt CB, Vazquez-Chona F, Vaughan DK, Organisciak DT. Extreme retinal remodeling triggered by light damage: implications for age related macular degeneration. Mol Vis. 2008; 14:782-806.

40. Xu HP, Tian N. Pathway-specific maturation, visual deprivation, and development of retinal pathway. Neuroscientist. 2004;10(4):337-346.

41. Xu HP, Tian N. Retinal ganglion cell dendrites undergo a visual activity-dependent redistribution after eye opening. J Comp Neurol. 2007;503(2):244-259.

42. Xu HP, Tian N. Glycine receptor-mediated synaptic transmission regulates the maturation of ganglion cell synaptic connectivity. J Comp Neurol. 2008;509(1):53-71.

43. Akula JD, Mocofanescu A, Ferguson RD, et al. Retinal remodeling in retinopathy of prematurity. Invest Ophthalmol Vis Sci. 2014;54:ARVO E-Abstract 3505.

44. Huang WC, Cideciyan AV, Roman AJ, et al. Inner and outer retinal changes in retinal degenerations associated with ABCA4 mutations. Invest Ophthalmol Vis Sci. 2014;55(3):1810-1822.

45. Palmer EA, Hardy RJ, Dobson V, et al. 15-year outcomes following threshold retinopathy of prematurity: final results from the multicenter trial of cryotherapy for retinopathy of prematurity. Arch Ophthalmol. 2005;123(3):311-318.

46. Early Treatment for Retinopathy of Prematurity Cooperative G, Dobson V, Quinn GE, et al. Grating visual acuity results in the early treatment for retinopathy of prematurity study. Arch Ophthalmol. 2011;129(7):840-846.

47. Hansen RM, Fulton AB. Dark-adapted thresholds at 10- and 30-deg eccentricities in 10-week-old infants. Vis Neurosci. 1995;12(3): 509-512.

48. Hansen RM, Fulton AB. The course of maturation of rod-mediated visual thresholds in infants. Invest Ophthalmol Vis Sci. 1999;40(8): $1883-1886$
49. Barnaby AM, Hansen RM, Moskowitz A, Fulton AB. Development of scotopic visual thresholds in retinopathy of prematurity. Invest Ophthalmol Vis Sci. 2007;48(10):4854-4860.

50. Fulton AB, Hansen RM, Moskowitz A, Barnaby AM. Multifocal ERG in subjects with a history of retinopathy of prematurity. Documenta ophthalmologica. Advances in ophthalmology. 2005;111(1):7-13.

51. Sutter EE, Tran D. The field topography of ERG components in man-I. The photopic luminance response. Vision Res. 1992;32(3):433-446.

52. Hood DC, Frishman LJ, Saszik S, Viswanathan S. Retinal origins of the primate multifocal ERG: implications for the human response. Invest Ophthalmol Vis Sci. 2002;43(5):1673-1685.

53. Yanni SE, Wang J, Chan M, et al. Foveal avascular zone and foveal pit formation after preterm birth. Br J Ophthalmol. 2012;96(7):961-966.

54. Lepore D, Molle F, Pagliara MM, et al. Atlas of fluorescein angiographic findings in eyes undergoing laser for retinopathy of prematurity. Ophthalmology. 2011;118(1):168-175.

55. Maldonado RS, O'Connell R, Ascher SB, et al. Spectral-domain optical coherence tomographic assessment of severity of cystoid macular edema in retinopathy of prematurity. Arch Ophthalmol. 2012;130(5): 569-578.

56. Fledelius HC. Pre-term delivery and subsequent ocular development. A 7-10 year follow-up of children screened 1982-84 for ROP. 3) Refraction. Myopia of prematurity. Acta Ophthalmol Scand. 1996;74(3): 297-300.

57. Fielder AR, Quinn GE. Myopia of prematurity: nature, nurture, or disease? Br J Ophthalmol. 1997;81(1):2-3.

58. O'Connor AR, Stephenson T, Johnson A, et al. Long-term ophthalmic outcome of low birth weight children with and without retinopathy of prematurity. Pediatrics. 2002;109(1):12-18.

59. Larsson EK, Rydberg AC, Holmstrom GE. A population-based study of the refractive outcome in 10-year-old preterm and full-term children. Arch Ophthalmol. 2003;121(10):1430-1436.

60. O'Connor AR, Stephenson TJ, Johnson A, Tobin MJ, Ratib S, Fielder AR. Change of refractive state and eye size in children of birth weight less than 1701 g. Br J Ophthalmol. 2006;90(4):456-460.

61. Quinn GE, Dobson V, Davitt BV, et al. Progression of myopia and high myopia in the early treatment for retinopathy of prematurity study: findings to 3 years of age. Ophthalmology. 2008;115(6):1058-1064.

62. Quinn GE, Dobson V, Davitt BV, et al. Progression of myopia and high myopia in the early treatment for retinopathy of prematurity study: findings at 4 to 6 years of age. JAAPOS. 2013;17(2):124-128.

63. Troilo D. Neonatal eye growth and emmetropisation - a literature review. Eye. 1992;6(Pt 2):154-160.

64. Troilo D, Wallman J. The regulation of eye growth and refractive state: an experimental study of emmetropization. Vision Res. 1991; 31(7-8):1237-1250.

65. Wallman J. Retinal control of eye growth and refraction. Prog Retin Res. 1993;12:133-153.

66. Westbrook AM, Crewther DP, Crewther SG. Cone receptor sensitivity is altered in form deprivation myopia in the chicken. Optom Vis Sci. 1999;76(5):326-338.

67. Chui TY, Bissig D, Berkowitz BA, Akula JD. Refractive Development in the "ROP Rat". J Ophthalmol. 2012;2012:Article ID 956705.

68. Zhang N, Favazza TL, Baglieri AM, et al. The rat with oxygen-induced retinopathy is myopic with low retinal dopamine. Invest Ophthalmol Vis Sci. 2013;54(13):8275-8284.

69. Mayer DL, Hansen RM, Moore BD, Kim S, Fulton AB. Cycloplegic refractions in healthy children aged 1 through 48 months. Arch Ophthalmol. 2001;119(11):1625-1628.

70. Zadnik K, Manny RE, Yu JA, et al. Ocular component data in schoolchildren as a function of age and gender. Optom Vis Sci. 2003;80(3): 226-236.

71. Hartnett ME. Pathophysiology and mechanisms of severe retinopathy of prematurity. Ophthalmology. 2015;122(1):200-210.

72. Hendrickson A, Troilo D, Djajadi H, Possin D, Springer A. Expression of synaptic and phototransduction markers during photoreceptor development in the marmoset monkey Callithrix jacchus. J Comp Neurol. 2009;512(2):218-231. 
73. Hendrickson AE. Primate foveal development: a microcosm of current questions in neurobiology. Invest Ophthalmol Vis Sci. 1994;35(8) 3129-3133.

74. Fulton AB, Dodge J, Hansen RM, Williams TP. The rhodopsin content of human eyes. Invest Ophthalmol Vis Sci. 1999;40(8):1878-1883.

75. Hood DC, Birch DG. Rod phototransduction in retinitis pigmentosa: estimation and interpretation of parameters derived from the rod a-wave. Invest Ophthalmol Vis Sci. 1994;35(7):2948-2961.
76. Lamb TD, Pugh EN Jr. A quantitative account of the activation steps involved in phototransduction in amphibian photoreceptors. J Physiol. 1992;449:719-758.

77. Pugh EN Jr., Lamb TD. Amplification and kinetics of the activation steps in phototransduction. Biochim Biophys Acta. 1993;1141(2-3):111-149.

78. Fulton AB, Rushton WA. The human rod ERG: correlation with psychophysical responses in light and dark adaptation. Vision Res. 1978;18(7):793-800.

Eye and Brain

\section{Publish your work in this journal}

Eye and Brain is an international, peer-reviewed, open access journal focusing on clinical and experimental research in the field of neuroophthalmology. All aspects of patient care are addressed within the journal as well as basic research. Papers covering original research, basic science, clinical and epidemiological studies, reviews and evaluations,

Submit your manuscript here: http://www.dovepress.com/eye-and-brain-journal

\section{Dovepress}

guidelines, expert opinion and commentary, case reports and extended reports are welcome. The manuscript management system is completely online and includes a very quick and fair peer-review system, which is all easy to use. Visit http://www.dovepress.com/testimonials.php to read real quotes from published authors. 